\title{
Lymphedema: From diagnosis to treatment
}

\author{
Oğuz Kayıran ${ }^{1,2}$, Carolyn De La Cruz ${ }^{3}$, Kaori Tane ${ }^{1}$, Atilla Soran ${ }^{1}$
}

\begin{tabular}{|c|c|}
\hline \multirow[t]{5}{*}{ ABSTRACT } & $\begin{array}{l}\text { Lymphedema is a chronic and progressive disorder resulting from impaired lymphatic system function. In developed } \\
\text { countries, upper extremity lymphedema is mainly the consequence of breast cancer surgery in which axillary lymph } \\
\text { node dissection and radiation alter upper extremity lymphatic flow. }\end{array}$ \\
\hline & $\begin{array}{l}\text { Diagnosis of lymphedema is made clinically. Nevertheless, there are numerous diagnostic tools available for disease } \\
\text { staging. Recently, a new technology namely magnetic resonance lymphangiography has emerged in the medical } \\
\text { field to assist in both diagnosis and management. }\end{array}$ \\
\hline & $\begin{array}{l}\text { There are non-surgical and surgical treatment options available. Non-surgical methods are always the first-line } \\
\text { treatment; however, surgical options can be explored in appropriate patients. Recent studies focus on the preven- } \\
\text { tion of lymphedema using surgical techniques utilizing axillary reverse mapping to delineate arm lymphatics from } \\
\text { axillary lymphatics. }\end{array}$ \\
\hline & $\begin{array}{l}\text { Finding the most suitable technique for each type of lymphedema with variable stages is one of the most compli- } \\
\text { cated decisions for practitioners. More studies are needed to reveal the exact biology of lymphedema to ensure } \\
\text { complete understanding of the disease and improve outcomes. }\end{array}$ \\
\hline & Keywords: Diagnosis, lymphedema, treatment \\
\hline
\end{tabular}

Cite this paper as:

Kayıran 0, De La Cruz C, Tane K, Soran A. Lymphedema: From diagnosis to treatment. Turk J Surg 2017; 33(2): 51-57

'Division of Breast Surgery and Lymphedema Program, MageeWomens Hospital of University of Pittsburgh Medical Center, Pittsburgh, USA ${ }^{2}$ Department of Plastic and Reconstructive Surgery, Baltalimani Hospital, İstanbul, Turkey

${ }^{3}$ Department of Plastic and Reconstructive Surgery, University of Pittsburgh Medical Center, Pittsburgh, USA

Address for Correspondence Atilla Soran

e-mail:asoran@upmc.edu

Received: 17.03.2017

Accepted: 20.03.2017

@C Copyright 2017 by Turkish Surgical Association

Available online at www.turkjsurg.com

\section{INTRODUCTION}

Lymphedema (LE) is the accumulation of protein-rich fluid in tissues. The impaired function of lymph vessels interrupts the drainage of lymphatic system that is a part of the circulatory system just like the arterial and venous structures. Lymph vessels remove excess fluid from tissues and transport it back to the circulation. In addition, the maturation of immune cells takes place in the lymphatic system; thus, it constitutes one of the most critical defense mechanisms throughout the body. Lymph capillaries are located in the dermis, woven like a cobweb, then drain to lymphatic vessels in the subcutaneous plane and ultimately to the deeper system and the thoracic duct.

Lymphedema can either be primary or secondary. Regardless of the etiology, it is clinically characterized with chronic swelling, localized pain, atrophic skin changes and secondary infections (1). However, the main devastating aspect of LE is the appearance of the affected limb that causes psychological morbidity. Primary LE is related to developmental abnormalities of the lymphatic system whereas secondary LE is attributed to the impairment of lymphatic vessels due to an acquired condition such as trauma, tumor, surgery or infection (Table 1). In developing countries, secondary LE is mainly due to infectionsinfestations influencing lymphatic channels. On the other hand, in developed countries, secondary LE occurs most commonly after surgical removal of lymph nodes for cancer treatment (2). Breast cancer is the most common cancer among women in the world and Breast Cancer Related Lymphedema (BCRL) occurs more often than any other type of LE (3). This review will focus on BCRL.

\section{Incidence}

Breast Cancer Related Lymphedema is detected in 7-77\% of patients who undergo axillary lymph node dissection (ALND) due to transection of lymph vessels as depicted in selected studies (4). Sentinel lymph node biopsy (SLNB) significantly reduces this risk to $3-7 \%(5,6)$. This incidence is based on multiple factors such as extent of disease, treatment modality (i.e. radiotherapy), and duration of follow-up $(6,7)$. In addition to these, a study revealed that patients with occupations that require extra upper extremity activity had the worst stage and grade LE clinically (3). In another study, factors associated with the development of BCRL included occupation, infection, and increased BMI. Immediate reconstruction of the breast was not found as a risk factor for BCRL (8). A recent study reported a risk assessment tool using these BCRL predictors (RATE-L), which included significant predictors such as post-mastectomy radiation, age above 65 years, and axillary dissection (9). 
Table 1. The etiology of lymphedema

\begin{tabular}{|lc|}
\hline Primary & Secondary \\
\hline Congenital & Trauma \\
\hline Milroy disease & Tumor \\
\hline Lymphedema praecox & Surgery \\
\hline Lymphedema tarda & Infection-infestation \\
\hline & Post-venous thrombosis \\
\hline
\end{tabular}

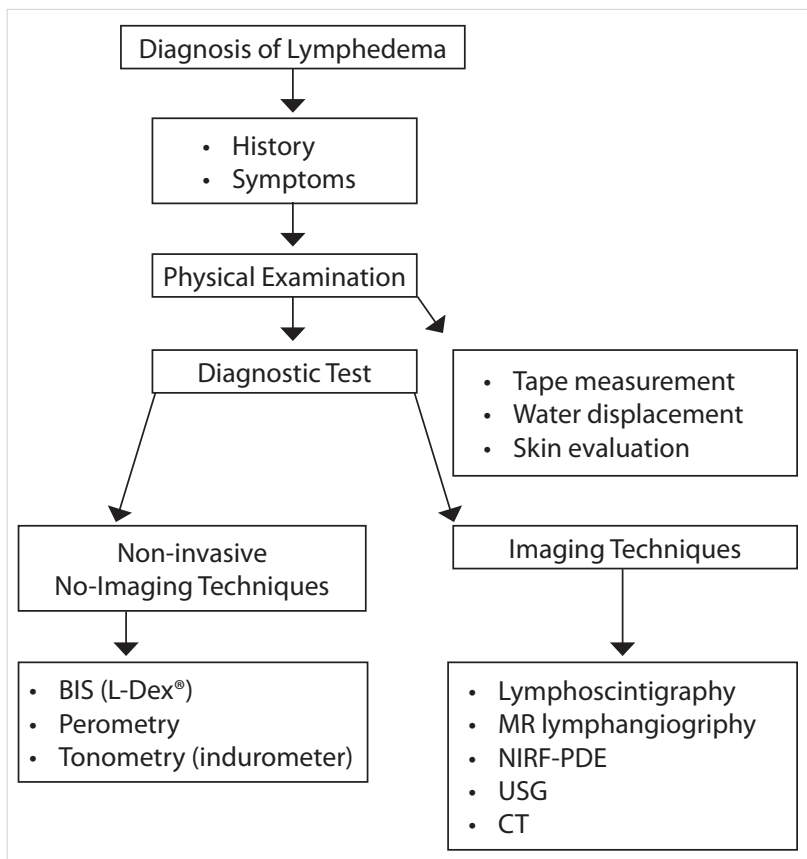

Figure 1. A scheme for the available options in the diagnosis of lymphedema

BIS: bioimpedence spectroscopy; MRI: magnetic resonance imaging; NIRF: near infra-red fluorescence imaging; PDE: photo dynamic eye (PDE; Hamamatsu Photonics K.K., Hamamatsu, Japan); USG: ultrasonography; CT: computed tomography

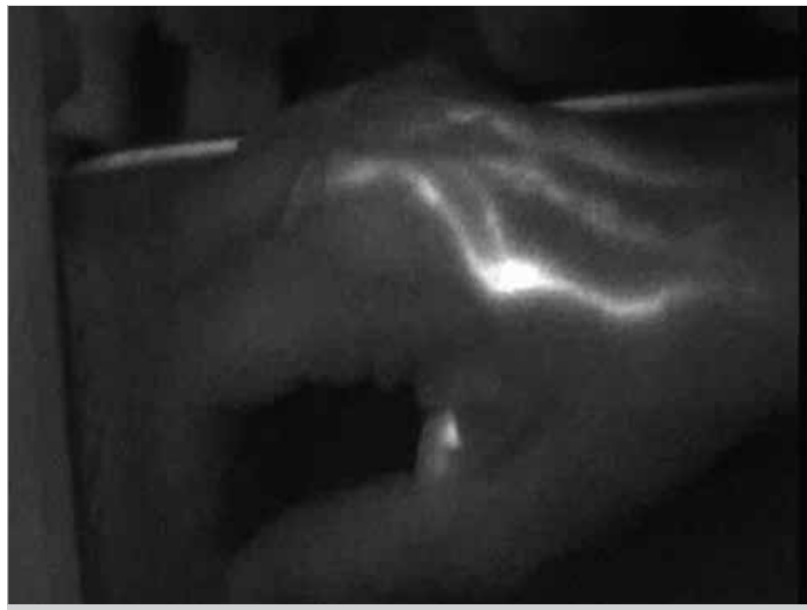

Figure 2. Near Infra-Red Fluorescence imaging (NIRF) for preoperative-intraoperative planning

\section{DIAGNOSIS}

Although there is no unique sign or criteria for defining $L E$, the diagnosis is usually made clinically by thorough evaluation and physical examination $(2,3,10)$. Family history is impor- chronic swelling, progressive atrophic skin changes, and recurrent infections. It is important to identify whether the swelling is transient or persistent. In one study, it was reported that one-third of initial swelling attacks were transient (10). Since effective treatment of LE can be established in early stages, accurate and timely diagnosis is crucial (11). History of trauma or surgery must be addressed clearly. Physical examination consists of volume and shape discrepancies, and skin changes among the extremities. Figure 1 outlines the alternatives in the diagnosis of LE.

Circumferential $(>2 \mathrm{~cm})$ and/or volume $(>200 \mathrm{~mL})$ differences between the affected and non-affected extremity can be performed to confirm the diagnosis (2). Volume can be measured by tape, water displacement or perometry (Perometer; Perosystems, Wuppertal, Germany) (12). Tape measurements require formula calculations; therefore, it is recommended that the measurements should be performed by the same person at defined intervals (12). It is mainly preferred on head and neck lymphedema follow-ups. Water displacement is an accurate method that is the gold-standard for volume assessment, especially on extremities (12); however, it is not used in daily practice because it doesn't delineate the affected area. If there is an open wound, it is not feasible to use this technique. Perometry is a computer-based study that calculates the volume of the affected limb via infra-red optical electronic scanner and can demonstrate small changes, but is expensive (2).

Non-invasive measurements (tonometry, bioimpedence spectroscopy) and imaging techniques (lymphoscintigraphy, ultrasonography, computed tomography, and magnetic resonance imaging) may aid in the detection of LE. The principal mechanism of a tissue tonometer is to evaluate tissue resistance by applying compression. Skin pliability and fibrosis can be measured with a tonometer. It gives a good idea about how changes occur during LE treatment. Tissue dielectric constant and tonometry can measure skin texture and resistance (1214). Ultrasonography, computed tomography and magnetic resonance imaging can show the presence of extra fluid within tissues (12).

Bioimpedence spectroscopy (BIS) is a new diagnostic tool to diagnose LE. It is a technique that assesses the extracellular fluid compartment before visible changes have settled (15). BIS mainly focuses on changes in electrical conductance of extracellular fluid. Since it depends on water content of the study area, advanced and fibrotic edema detected in late-stage LE may not be diagnosed properly by BIS (12). In other words, $\mathrm{BIS}$ is reliable in early-stage BCRL. A prospective observational study demonstrated the impact of L-Dex ${ }^{\circledast}$ (L-Dex; Impedimed, Brisbane, Australia) measurements in identification of subclinical BCRL and its use in routine clinical practice (16). L-Dex ${ }^{\circledast}$ is the score representing extracellular fluid ratio of the affected limb to the unaffected limb, and is sensitive in predicting the onset of LE up to 10 months prior to clinical diagnosis (15).

Lymphoscintigraphy is a nuclear medicine study and demonstrates slow or absent lymph flow usually in later stages of LE (12). Technetium $99 \mathrm{~m}$ sulfur colloid is injected intradermally and the transit time to lymph node basins can be measured; however, subdermal lymphatics cannot be assessed. A new technique for imaging lymph vessels is Near Infra-Red Fluo- 

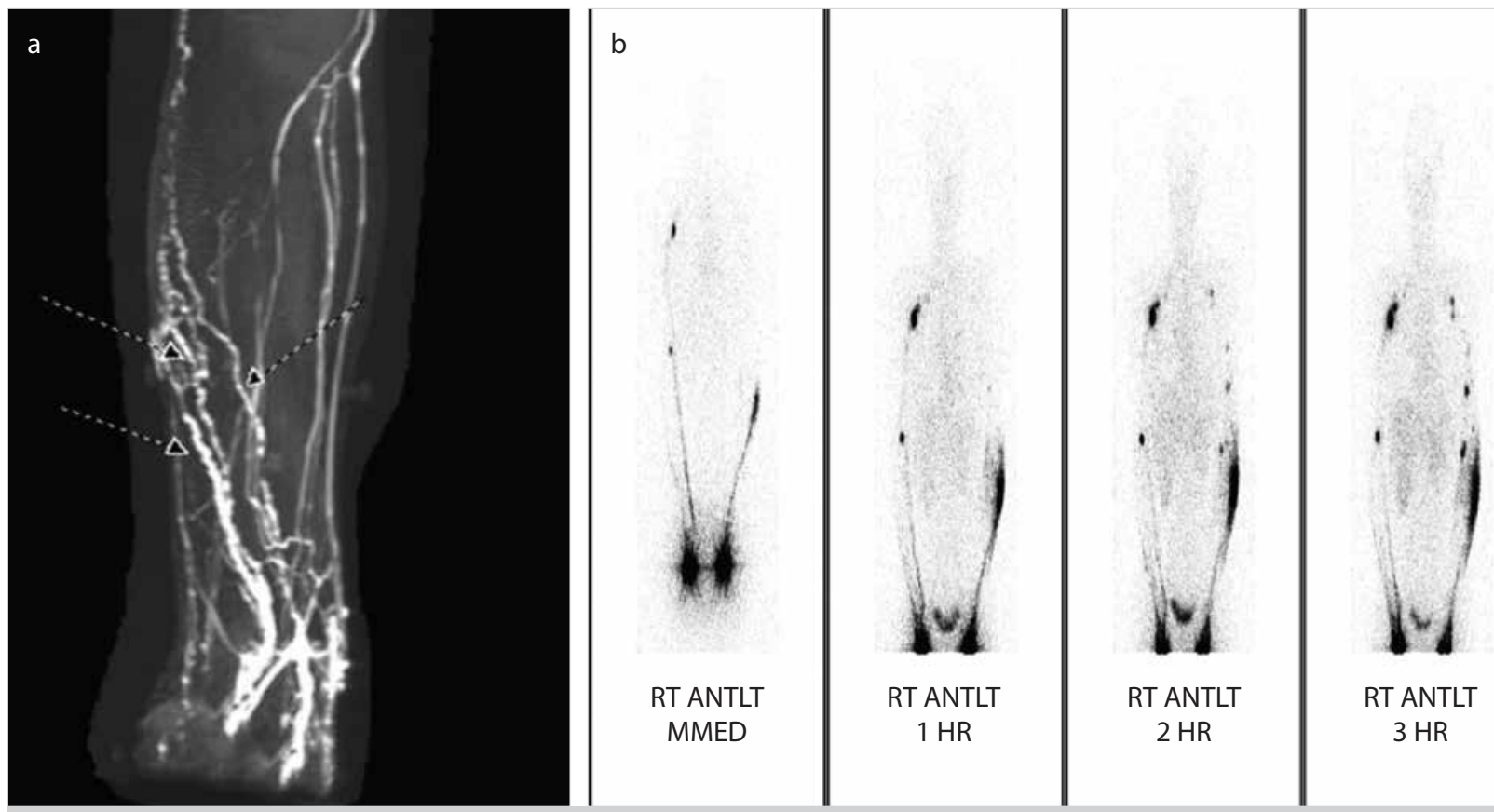

Figure 3. a, b. (a) Magnetic resonance lymphangiography. Three irregular tubular structures extending from the dorsal aspect of the wrist to the lateral/dorsal aspect of the right forearm are compatible with enlarged lymphatics. These vessels are subcutaneous and measure up to 3-4 $\mathrm{mm}$ in caliber. In the lateral and ventral aspect of the mid-portion of the forearm (in proximity to the expected location of two lymphovenuler anastomosis), there seems to be communication between these lymphatics and small venules, branches of the basilic and ventral branches of the cephalic vein. There is minimal dermal backflow in the lateral aspect of the mid-portion of the right forearm. (b) Lymphoscintigraphy. Abnormally delayed lymphatic transit and dermal backflow are identified in the left forearm

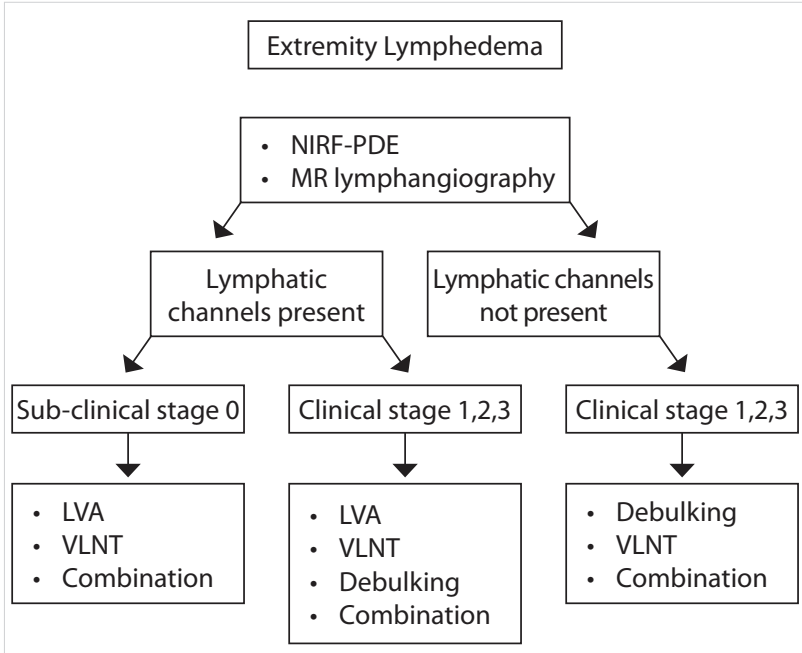

Figure 4. An algorithm for the treatment of lymphedema according to magnetic resonance lymphangiography LVA: lymphaticovenular bypass; VLNT: vascularized lymph node transfer

rescence Imaging (NIRF) by using indocyanine green. This dynamic test allows visualization of superficial lymphatic flow and functioning lymphatic vessels; thus, finds abnormalities at early stages. It can be used to stage the severity of disease and for preoperative-intraoperative planning $(17,18)$ (Figure 2). Lymphography is another entity where radio-opaque material is directly injected into peripheral lymph vessels. This technique is rarely done due to the risk of damaging lymph vessels.

Magnetic resonance lymphangiography is a new entity that involves the injection of Gadolinium into the hand or foot to

\begin{tabular}{|c|c|c|}
\hline Stage & Description & Characteristics \\
\hline 0 & Latent & $\begin{array}{l}\text { Some damage to lymphatics; } \\
\text { No visible edema yet }\end{array}$ \\
\hline 1 & $\begin{array}{l}\text { Spontaneously } \\
\text { reversible, } \\
\text { acute phase }\end{array}$ & $\begin{array}{l}\text { Pitting edema; reversible with elevation } \\
\text { of the arm. Usually, upon waking in the } \\
\text { morning, the limb(s) or affected area is } \\
\text { normal or almost normal size }\end{array}$ \\
\hline 2 & $\begin{array}{l}\text { Spontaneously } \\
\text { irreversible, } \\
\text { chronic phase }\end{array}$ & $\begin{array}{l}\text { Spongy consistency and is "non-pitting," } \\
\text { Fibrosis found in Stage } 2 \text { lymphedema } \\
\text { marks the beginning of the hardening } \\
\text { of the limbs and increasing size }\end{array}$ \\
\hline 3 & $\begin{array}{l}\text { Elephantiasis; } \\
\text { irreversible, } \\
\text { end-stage }\end{array}$ & $\begin{array}{l}\text { Irreversible and usually the limb(s) } \\
\text { is/are very large. The tissue is hard } \\
\text { (fibrotic) and unresponsive; consider } \\
\text { debulking surgey at this stage }\end{array}$ \\
\hline
\end{tabular}

clarify the course of lymphatics. Gadolinium can also get into the venous system making the interpretation of lymphatic channels difficult (19). Magnetic resonance venogram and ferumoxytole (Feraheme; Advanced Magnetics, Cambridge, MA, USA) are used to help to differentiate lymphatics from veins $(19,20)$. With the advent of magnetic resonance lymphangiography, the severity of LE can be delineated while the anatomy of the lymphatic channels and the status of the soft tissues can also be depicted (20) (Figure 3). We suggested an algorithm for the management of patients with LE, by using Magnetic resonance lymphangiography and LE stage in this review (Figure 4). 
Table 3. Treatment options in lymphedema

\begin{tabular}{|c|c|}
\hline Non-surgical treatments & Surgical treatments \\
\hline Complete decongestive therapy & Reductive techniques \\
\hline Manual lymph drainage & Direct excision \\
\hline Compression therapy & Liposuction \\
\hline Exercise & Physiological techniques \\
\hline Skin care & Lymphatico-lymphatic by-pass \\
\hline Compression garments & Lymphatico-venous by-pass \\
\hline Advanced pneumatic & Lymph node transfer \\
\hline compression therapy & \\
\hline Laser therapy
\end{tabular}

The International Society of Lymphology classified LE into 4 stages to overcome multiple classification schemes and obtain a consensus (3) (Table 2). In addition, Campisi et al. (21) proposed a staging system consisting of 3 stages, especially for elders.

\section{TREATMENT}

The management of LE consists of accurate diagnosis, successful classification and patient education. Unfortunately, there is no absolute cure for LE. On the other hand, effective treatment is available. Two main modalities include non-surgical and surgical options (Table 3). The mainstays of non-surgical LE treatment modalities are complete decongestive therapy (CDT), compression therapy, advanced pneumatic compression pumps and exercise. These treatments are effective mainly in early-stage LE (2). There is a global trend for surgical intervention and surgical techniques including physiological and reductive methods.

\section{Non-Surgical Treatments}

Patient education is both crucial and mandatory (22). Self-care and risk-reductive practices, self-lymph drainage, skin care, proper alignment of bandages and garments, good nutrition, exercise and weight control are the basics prior to LE treatment (12).

\section{Complete Decongestive Therapy}

Complete Decongestive Therapy (CDT) is considered the goldstandard treatment method in the management of LE and includes two phases: reductive (phase 1) and maintenance (phase 2) (23). CDT is a good option in decreasing LE volume and includes manual lymph drainage, compression therapy, physical exercise, skin care as self-management, followed by wearing compression garments $(23,24)$. Although it is safe and effective in most patients, it is expensive, time-consuming and needs certified therapists. In addition, patient compliance to long-term CDT is challenging. Nevertheless, CDT can be individualized with modifications until the lymphedematous volume reduction has been maximized.

Manual lymph drainage (MLD): MLD is a hands-on technique and differs from standard massage by orienting the lymphedematous fluid to proper functioning lymphatics (24).

Compression Therapy: Compression therapy includes effective gradient compression with tubular bandaging on the af- fected limb (25). Short-stretch bandages provide low "resting pressure" when the patient is at rest and "working pressure" which allows muscle contractions to direct interstitial fluid flow $(23,25)$. These bandages also reduce fibrosis in the skin (25). Compression garments are different from compression bandages and are preferred in long-term treatment.

Exercise: Specific exercise is beneficial for LE patients (12). It is recommended that compression bandages or garments should be worn during activity (12). Patients with LE or people at-risk for LE are encouraged to exercise. A meta-analysis showed that active exercising reduces edema volume in BCRL (26). A recent pilot study demonstrated that yoga has beneficial effects on an individuals' posture and strength (27).

Skin Care: Establishing proper hygiene is important for patients with LE. Low $\mathrm{pH}$ moisturizers are recommended to overcome skin cracking and drying, in order to prevent entrance of microorganisms (12).

Compression Garments: Initial control of LE can be achieved with the use of compression bandages. Long term control is obtained with compression garments (12). The type of the garment depends on the body part. Patients should have several garments to alternate and ensure the proper pressure and hygienic control. Accurate fitted garments are essential. Some patients require additional coverage night-or-day to control or reduce LE (12).

Advanced New Generation Pneumatic Compression Therapy Advanced Pneumatic Compression (APC) therapy can be used as an adjunct to CDT either in early or late phases $(12,28)$. It mimics the pump effect of muscular contraction on lymphatic system (2). Ranging between 35 and $180 \mathrm{~mm}-\mathrm{Hg}$, pump pressures are adjusted to mostly $20-60 \mathrm{~mm}-\mathrm{Hg}(2,12)$. The pressure must be individualized in order to prevent skin damage during application. APC therapy was found beneficial in reducing LE, whereas compression sleeves prevented additional swelling without influencing volume reduction (2).

\section{Laser Therapy}

A number of randomized trials have reported that Low-Level Laser Therapy (LLLT) improved measurable physical parameters as well as subjective pain scores (29). LLLT increases lymphatic drainage by stimulating the formation of new lymph vessels, by improving lymphatic motricity, and by preventing formation of fibrotic tissue (30). Usually, LLLT is used in combination with CDT. Most studies did not report any adverse events to participants, although one study stated development of cellulitis in LLLT patients as an adverse event (31). Its causal relationship to LLLT was unknown.

\section{SURGICAL TREATMENTS}

\section{Reductive Techniques}

Direct excision: These techniques include removal of lymphedematous tissue. Previously described methods such as the Charles procedure include complete removal of all subcutaneous tissue and skin grafting (32). This method, although effective at volume reduction, can be quite disfiguring. It also can require blood transfusions and lengthy wound healing. Another technique used in the past involved buried dermal flaps 


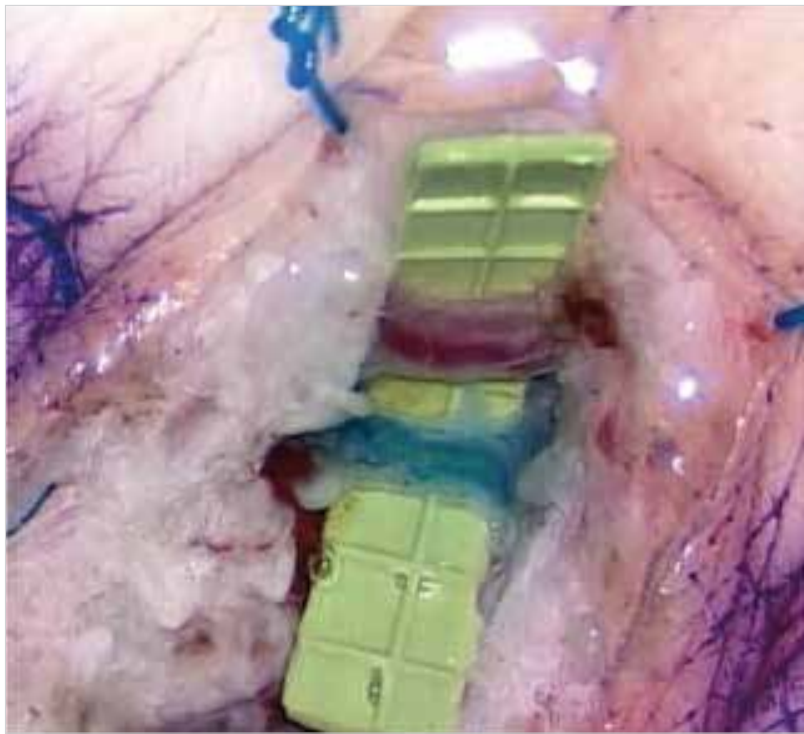

Figure 5. Lymphovenous anastomosis. Please note supermicrosurgery is used to establish such an anastomosis

with variable success (33). Direct excision techniques may involve full-thickness skin grafting (FTSG) or vacuum-assisted closure therapy (2). In extreme cases, these techniques allow for improvement in quality of life.

Liposuction: Surgical debulking of the affected extremity using liposuction has been shown to be very effective at reducing the volume to near normal (34). This technique has been used in both congenital and acquired LE. It has also been used in cases of lipedema. It has been reported that liposuction technique provides long standing reduction in extremity size as compared to the normal side (35). This technique requires patient compliance with compression therapy to prevent regression. Patients considering this technique should undergo pre-operative conservative management with no pitting edema (34). It has been shown to be effective both in the upper and lower extremity, although it is more effective in the upper extremity. It is known that adipose tissue functions as a crucial organ and a cytokine-activated cell in LE (36). The removal of adipose tissue using liposuction does not affect the already decreased lymph transport system in LE (34). Moreover, a significant improvement was detected in skin blood flow and quality of life after liposuction $(37,38)$. Its complications include infection, skin necrosis and recurrence.

\section{PHYSIOLOGIC TECHNIQUES}

Lymphatic venous anastomosis, lymphatico-lymphatic bypass, and lymph node transfer can be listed as physiologic methods. Many of these methods use recent developments in technology to assist in identifying lymphatic channels and lymph nodes $(2,39)$.

\section{Lymphatic Venous Anastomosis (LVA) or Bypass}

LVA was first described in an animal model with several human studies to follow $(40,35)$. This technique involves the creation of connections between the lymphatic system and the venous system in the distal or proximal extremity. Superficial or deep lymphatics are anastomosed with neighboring veins. Fluorescence is used to help identify the lymphatic system and an operating microscope is used to assist in microsurgery (41). Single or multiple LVA's have been reported by different authors using differing surgical sites $(39,42-44)$. Supermicrosurgery (anastomosis less than $0.8 \mathrm{~mm}$ vessels) is used in this technique, in which lymphatic vessels and adjacent venules are anastomosed, mostly in an end-to-end fashion $(39,43)$ (Figure 5). Variations on the configuration of anastomosis type were described in several studies with variable success rates $(45,46)$. Studies have reported improvement in patients both subjectively and objectively. In general, LVA's have been shown to be a safe technique for the management of $\operatorname{LE}(39,43)$.

Vascularized Lymph Node Transfer: Vascularized lymph node transfer was first introduced in animal models (47). It has recently been applied to humans with gaining popularity. There are different options for lymph node transfer, namely the location of the donor and the recipient sites. Options for lymph node harvest include the lateral thoracic region, groin, submental region, supraclavicular region and intraabdominal lymph nodes $(44,48,49)$. Each donor site has its particular anatomic advantages and disadvantages, and contains varying number of lymph nodes ranging from 1-10. The lymph nodes can be harvested together with a portion of the skin if necessary. These operations require microsurgical skills to perform an arterial and venous anastomosis to provide blood supply to the transferred tissue. The results of lymph node transfer are quite promising and have been shown to provide both objective and subjective improvements (35).

One consideration for lymph node transfer is the concern for possible LE at the donor site (50). Reverse lymph node mapping, originally described as a technique to refine axillary dissection, can be used to minimize lymph node harvest related morbidity (51). It allows differential identification of nodes which drain the neighboring extremity in addition to the ones that are included in the tissue to be removed. Reverse lymph node mapping involves the use of the photodynamic eye, Technetium and ICG dye. Using this technique, the surgeon can be reassured that no lymph nodes are removed that drain the extremity (51). Clinically, the benefit of lymph node transfer is to restore immunologic function to the extremity and improve fluid drainage. However, the action mechanism of lymph node transfers is poorly understood. The transferred nodes have been shown to be active in a number of studies. One proposed mechanism suggests that the new lymph nodes act as "pumps" which filter the surrounding fluid (52). The best site for lymph node implantation is currently unknown. In some cases, the nodes have been placed distally whereas in others they were implanted proximally (52). Welldesigned controlled prospective studies are needed to clarify if the suggested functional surgical methods are beneficial in the long-term.

A variety of lymph node transfers includes a tissue portion to be transferred with lymph nodes. Such examples include transferring the lower abdominal tissue in case of total breast anatomical reconstruction (TBAR) and latissimus dorsi flaps with lymph nodes. In such cases, both the breast and the lymph nodes are reconstructed $(44,50,53)$. Other types of flaps such as those harvested intraabdominally carry lymphatic tissue from the omentum (49). These can be harvested either by open surgery or laparoscopically. 


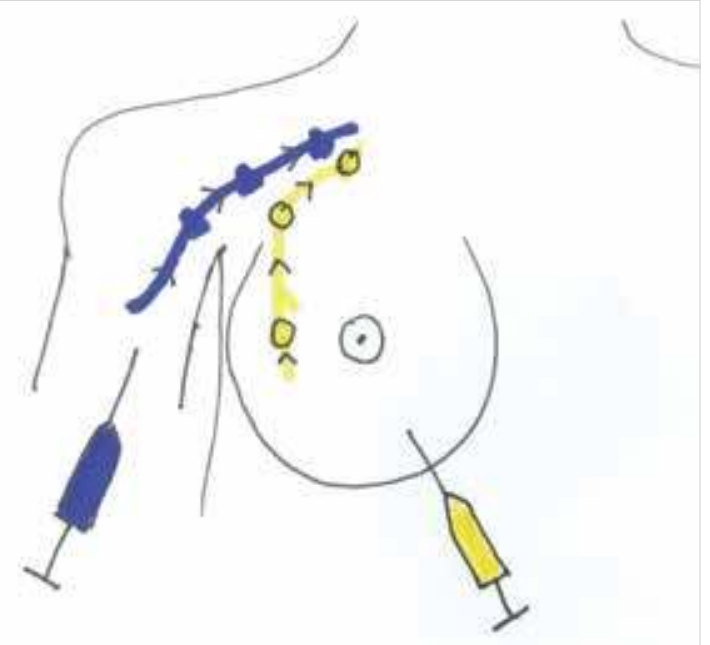

Figure 6. The mapping of axillary lymphatics. A radioisotope is injected into the breast, whereas blue-dye is administered subcutaneously to the upper arm. The lymphatic flow of the breast and arm is separately revealed

\section{Intraoperative Considerations}

The nodal status defines one of the most important prognostic factors in breast cancer. However, although necessary, axillary dissection may compromise the lymphatic system thus contributing to the development of LE.

Recently, the lymphatic drainage of the arm and breast tissue were studied and it was found that preserving arm lymphatics during SLNB and/or ALND via a new concept called axillary reverse mapping (ARM) may reduce the risk of $B C R L(4,54,55)$. ARM is based on the hypothesis that drainage of arm lymphatics differs from that of breast lymphatics $(4,54)$. However, it was shown that lymphatic interconnections exist in the axilla between arm and breast lymphatics (56). The technique of mapping the arm and breast lymphatics is comprised of radioisotope injection to the breast and blue dye injection to the upper arm (Figure 6). The lymphatic pathways and interconnections are determined. When a crossover is identified, blue nodes should be removed (55). ARM reduced BCRL when compared with conventional breast cancer surgeries, nevertheless, randomized controlled studies are needed (55).

\section{CONCLUSION}

Breast Cancer Related Lymphedema is a devastating disease affecting millions of women. Its treatment is aimed at curing the disease and reducing recurrence rate. However, treatment methods create both physical and psychological morbidity to the patients. BCRL influences daily activities and affects patient self-esteem in various ways. Modern surgical and nonsurgical techniques offer numerous methods for the patients to overcome BCRL. In the future, we hope to ensure $100 \%$ success in the control or elimination of BCRL. Until then, the exact biology, pathogenesis of lymphatic system diseases and the treatment options require further research to be able to understand this devastating disease.

Peer-review: Externally peer-reviewed.

Author Contributions: Concept - O.K., C.D.L.A., K.T., A.T.; Design - O.K., C.D.L.A., K.T., A.T.; Supervision - O.K., C.D.L.A., K.T., A.T.; Resource - O.K., C.D.L.A., K.T., A.T.; Materials - O.K., C.D.L.A., K.T., A.T.; Data Collection and/ or Processing - O.K., C.D.L.A., K.T., A.T.; Analysis and/or Interpretation - O.K., C.D.L.A., K.T., A.T.; Literature Search - O.K., C.D.L.A., K.T., A.T.; Writing Manuscript - O.K., C.D.L.A., K.T., A.T.; Critical Reviews - O.K., C.D.L.A., K.T. ,A.T.

Conflict of Interest: No conflict of interest was declared by the authors.

Financial Disclosure: The authors declared that this study has received no financial support.

\section{REFERENCES}

1. Basta MN, Gao LL, Wu LC. Operative treatment of peripheral lymphedema: a systematic meta-analysis of the efficacy and safety of lymphovenous microsurgery and tissue transplantation. Plast Reconstr Surg 2014; 133: 905-913. [CrossRef]

2. Grabb and Smith's Plastic Surgery, $7^{\text {th }}$ edition. In: Thorne $\mathrm{CH}$, editor, Wolters Kluwer Health, 2013. Lymphedema: Diagnosis and treatment, Chapter 97 p. 980-988.

3. Tahan G, Johnson R, Mager L, Soran A. The role of occupational upper extremity use in breast cancer related upper extremity lymphedema. J Cancer Surviv 2010; 4: 15-19. [CrossRef]

4. Noguchi M. Axillary reverse mapping for breast cancer. Breast Cancer Res Treat 2010; 119: 529-535. [CrossRef]

5. Francis WP, Abghari P, Du W, Rymal C, Suna M, Kosir MA. Improving surgical outcomes: standardizing the reporting of incidence and severity of acute lymphedema after sentinel lymph node biopsy and axillary lymph node dissection. Am J Surg 2006; 192: 636-639. [CrossRef]

6. DiSipio T, Rye $S$, Newman B, Hayes S. Incidence of unilateral arm lymphoedema after breast cancer: a systematic review and metaanalysis. Lancet Oncol 2013; 14: 500-515. [CrossRef]

7. Armer JM, Stewart BR. Post-breast cancer lymphedema: incidence increases from 12 to 30 to 60 months. Lymphology 2010; 43: 118-127.

8. Gur AS, Unal B, Ahrendt G, Gimbel ML, Kayiran O, Johnson R, et al. Risk Factors for Breast Cancer-Related Upper Extremity Lymphedema: Is Immediate Autologous Breast Reconstruction one of them? Cent Eur J Med 2009; 4: 65-70. [CrossRef]

9. Basta MN, Wu LC, Kanchwala SK, Serletti JM, Tchou JC, Kovach SJ, et al. Reliable prediction of postmastectomy lymphedema: the risk assessment tool evaluating lymphedema. Am J Surg 2016 Sep 7. doi: 10.1016/j.amjsurg.2016.08.016. [Epub ahead of print] [CrossRef]

10. Kim M, Shin KH, Jung SY, Lee $S$, Kang HS, Lee ES, et al. Identification of Prognostic Risk Factors for Transient and Persistent Lymphedema after Multimodal Treatment for Breast Cancer. Cancer Res Treat 2016; 48: 1330-1337. [CrossRef]

11. Bernas M, Askew RL, Armer JM, Cormier JN. Lymphedema: How do we diagnose and reduce the risk of this dreaded complication of breast cancer treatment? Curr Breast Cancer Rep 2010; 2: 53-58. [CrossRef]

12. NLN Medical Advisory Committee. The diagnosis and the treatment of lymphedema. In: Position statement of the national lymphedema network. Feb 2011. Available from: http://www. lymphnet.org/pdfDocs/nlntreatment.pdf.

13. Mayrovitz, $\mathrm{H}$. Assessing lymphedema by tissue indentation force and local tissue water. Lymphology 2009; 42: 88-98.

14. Liu NF, Olszewski W. Use of tonometry to assess lower extremity lymphedema. Lymphology 1992; 25: 155-158.

15. Cornish BH, Chapman M, Hirst C, Mirolo B, Bunce IH, Ward LC, et al. Early diagnosis of lymphedema using multiple frequency bioimpedance. Lymphology 2001; 34: 2-11.

16. Soran A, Ozmen T, McGuire KP, Diego EJ, McAuliffe PF, Bonaventura $M$, et al. The importance of detection of subclinical lymphedema for the prevention of breast cancer-related clinical lymphedema after axillary lymph node dissection; a prospective observational study. Lymphat Res Biol 2014; 12: 289-294.[CrossRef]

17. Narushima $M$, Yamamoto $T$, Ogata F, Yoshimatsu $H$, Mihara $M$, Koshima I. Indocyanine green lymphography findings in limb lymphedema. J Reconstr Microsurg 2016; 32: 72-79. 
18. Yamamoto T, Yamamoto N, Azuma S, Yoshimatsu H, Seki Y, Narushima $M$, et al. Near-infrared illumination system-integrated microscope for supermicrosurgical lymphaticovenular anastomosis. Microsurgery 2014; 34: 23-27. [CrossRef]

19. Neligan PC, Kung TA, Maki JH. MR lymphangiography in the treatment of lymphedema. J Surg Oncol 2017; 115: 18-22. [CrossRef]

20. Mitsumori LM, McDonald ES, Neligan PC, Maki JH. Peripheral Magnetic Resonance Lymphangiography: Techniques and Applications. Tech Vasc Interv Radiol 2016; 19: 262-272. [CrossRef]

21. Campisi C, Campisi S, Accogli S, Campisi C, Boccardo F. Lymphedema staging and surgical indications in geriatric age. BMC Geriatrics 2010; 10: A50 [CrossRef]

22. Fu MR, Axelrod D, Haber J. Breast Cancer-Related Lymphedema: Information, Symptoms, and Risk Reduction Behaviors. J Nurs Scholarsh 2008; 40: 341-348. [CrossRef]

23. Mayrovitz HN. The standard of care for lymphedema: current concepts and physiological considerations. Lymphat Res Biol 2009; 7: 101-108. [CrossRef]

24. Williams AF, Vadgama A, Franks PJ, Mortimer PS. A randomized controlled crossover study of manual lymphatic drainage therapy in women with breast cancer-related lymphoedema. Eur J Cancer Care (Engl). 2002; 11: 254-261. [CrossRef]

25. European Wound Management Association (EWMA). Focus Document: Lymphoedema bandaging in practice. London: MEP Ltd, 2005.

26. Rogan S, Taeymans J, Luginbuehl H, Aebi M, Mahnig S, Gebruers $\mathrm{N}$. Therapy modalities to reduce lymphoedema in female breast cancer patients: a systematic review and meta-analysis. Breast Cancer Res Treat 2016; 159: 1-14. [CrossRef]

27. Fisher MI, Donahoe-Fillmore B, Leach L, O'Malley C, Paeplow C, Prescott T, Merriman H. Effects of yoga on arm volume among women with breast cancer related lymphedema: A pilot study. J Bodyw Mov Ther 2014; 18: 559-565. [CrossRef]

28. Szuba A, Achalu R, Rockson SG. Decongestive lymphatic therapy for patients with breast carcinoma-associated lymphedema. A randomized, prospective study of a role or adjunctive intermittent pneumatic compression. Cancer 2002; 95: 2260-2267. [CrossRef]

29. Smoot B, Chiavola-Larson L, Lee J, Manibusan H, Allen DD. Effect of low-level laser therapy on pain and swelling in women with breast cancer-related lymphedema: a systematic review and meta-analysis. J Cancer Surviv 2015; 9: 287-304. [CrossRef]

30. Robijns J, Censabella S, Bulens P, Maes A, Mebis J. The use of lowlevel light therapy in supportive care for patients with breast cancer: review of the literature. Lasers Med Sci 2017; 32: 229-242. [CrossRef]

31. Dirican A, Andacoglu O, Johnson R, McGuire K, Mager L, Soran A. The short-term effects of low-level laser therapy in the management of breast-cancer-related lymphedema. Support Care Cancer 2011; 19: 685-690. [CrossRef]

32. Charles RH. Elephantiasis scroti. In: Latham A, English TC, eds. A System of Treatment, Vol. III. London: Churchill Livingstone; 1912: 504-513.

33. Thompson N. Buried dermal flap operation for chronic lymphedema of the extremities: Ten-year survey of results in 79 cases. Plast Reconstr Surg 1970; 45: 541-548. [CrossRef]

34. Brorson H. From lymph to fat: complete reduction of lymphoedema. Phlebology 2010; 25 (Suppl 1): 52-63. [CrossRef]

35. Carl HM, Walia G, Bello R, Clarke-Pearson E, Hassanein AH, Cho B, et al. Systematic Review of the Surgical Treatment of Extremity Lymphedema. J Reconstr Microsurg. 2017 Feb 24. doi: 10.1055/s0037-1599100. [Epub ahead of print] [CrossRef]

36. Pond CM. Adipose tissue and the immune system. Prostaglandins Leukot Essent Fatty Acids 2005; 73: 17-30. [CrossRef]

37. Brorson $\mathrm{H}$, Svensson $\mathrm{H}$. Skin blood flow of the lymphoedematous arm before and after liposuction. Lymphology 1997; 30: 165-172.
38. Brorson H, Ohlin K, Olsson G, Langstrom G, Wiklund I, Svensson $\mathrm{H}$. Quality of life after liposuction and conservative treatment of arm lymphoedema. Lymphology 2006; 39: 8-25.

39. Chang DW. Lymphaticovenular bypass for lymphedema management in breast cancer patients: a prospective study. Plast Reconstr Surg. 2010; 126: 752-758. [CrossRef]

40. Laine JB, Howard JM. Experimental lymphatic-venous anastomosis. Surg Forum 1963; 14: 111-112.

41. Furukawa H, Osawa M, Saito A, Hayashi T, Funayama E, Oyama $A$, et al. Microsurgical lymphaticovenous implantation targeting dermal lymphatic backflow using indocyanine green fluorescence lymphography in the treatment of postmastectomy lymphedema. Plast Reconstr Surg 2011; 127: 1804-1811. [CrossRef]

42. Campisi C, Boccardo F. Lymphedema and microsurgery. Microsurgery 2002; 22: 74-80. [CrossRef]

43. Koshima I, Inagawa K, Urushibara K, Moriguchi T. Supermicrosurgical lymphaticovenular anastomosis for the treatment of lymphedema in the upper extremities. J Reconstr Microsurg 2000; 16: 437-442. [CrossRef]

44. Becker C, Vasile JV, Levine JL, Batista BN, Studinger RM, Chen $\mathrm{CM}$, et al. Microlymphatic surgery for the treatment of iatrogenic lymphedema. Clin Plast Surg 2012; 39: 385-398. [CrossRef]

45. Campisi C. Use of autologous interposition vein graft in management of lymphedema: Preliminary experimental and clinical observations. Lymphology 1991; 24: 71-76.

46. Yamamoto T, Narushima M, Kikuchi K, Yoshimatsu H, Todokoro T, Mihara $\mathrm{M}$, et al. Lambda-shaped anastomosis with intravascular stenting method for safe and effective lymphaticovenular anastomosis. Plast Reconstr Surg 2011; 127: 1987-1992. [CrossRef]

47. Chen HC, O'Brien BM, Rogers IW, Pribaz JJ, Eaton CJ. Lymph node transfer for the treatment of obstructive lymphoedema in the canine model. Br J Plast Surg. 1990; 43: 578-586. [CrossRef]

48. Mardonado AA, Chen R, Chang DW. The use of supraclavicular free flap with vascularized lymph node transfer for treatment of lymphedema: A prospective study of 100 consecutive cases. J Surg Oncol 2017; 115: 68-71. [CrossRef]

49. Nakajima E, Nakajima R, Tsukamoto S, Koide $Y$, Yarita T, Kato H. Omental transposition for lymphedema after a breast cancer resection: report of a case. Surg Today 2006; 36: 175-179. [CrossRef]

50. Pons G, Masia J, Loschi P, Nardulli ML, Duch J. A case of donorsite lymphoedema after lymph node-superficial circumflex iliac artery perforator flap transfer. J Plast Reconstr Aesthet Surg 2014; 67: 119-123. [CrossRef]

51. Dayan JH, Dayan E, Smith ML. Reverse lymphatic mapping: new technique for maximizing safety in vascularized lymph node transfer. Plast Reconstr Surg 2015; 135: 277-85. [CrossRef]

52. Lin $\mathrm{CH}$, Ali R, Chen SC, Wallace $\mathrm{C}$, Chang YC, Chen HC, et al. Vascularized groin lymph node transfer using the wrist as a recipient site for management of postmastectomy upper extremity lymphedema. PlastReconstr Surg 2009; 123: 12651275. [CrossRef]

53. Inbal A, Teven CM, Chang DW. Latissimus dorsi flap with vascularized lymph node transfer for lymphedema treatment: Technique, outcomes, indications and review of literature. J Surg Oncol 2017; 115: 72-77. [CrossRef]

54. Thompson M, Korourian S, Henry-Tillman R, Adkins L, Mumford S, Westbrook KC, et al. Axillary reverse mapping (ARM): a new concept to identify and enhance lymphatic preservation. Ann Surg Oncol2007; 14: 1890-1895. [CrossRef]

55. Tummel E, Ochoa D, Korourian S, Betzold R, Adkins L, McCarthy $M$, et al. Does Axillary Reverse Mapping Prevent Lymphedema After Lymphadenectomy? Ann Surg 2017; 265: 987-992. [CrossRef]

56. Suami H, Taylor GI, Pan WR. The lymphatic territories of the upper limb: anatomical study and clinical implications. Plast Reconstr Surg 2007; 119: 1813-1822.[CrossRef] 